\title{
DESENVOLVIMENTO DE UM FOTÔMETRO DE BAIXO CUSTO PARA DETERMINAÇÃO DE TEOR ALCOÓLICO EM CERVEJA COMO FERRAMENTA DE ANÁLISE DE PROCESSO
}

\author{
LEITE MONIQUE J. L. ${ }^{1}$, FILHO ADEMAR L. Da S. ${ }^{1}$, BARROS IALY S. ${ }^{2}$, SILVA JOSIVAN P. ${ }^{2}$ e \\ SOUZA THIBÉRIO P. C. ${ }^{1,2}$ \\ ${ }^{1}$ Universidade Federal Rural de Pernambuco, Departamento de Engenharia de Alimentos \\ ${ }^{2}$ Universidade Federal de Pernambuco, Departamento de Engenharia Química \\ E-mail para contato: thiberio_souza@hotmail.com
}

RESUMO - Os diodos emissores de luz (LED) Red-Green-Blue (RGB) têm proporcionado muitas vantagens quando utilizados em instrumentação óptica. Já os Light Dependent Resistor (LDR) são componentes eletrônicos passivos do tipo resistor variável de intensidade de luz. Os fotômetros simples, portáteis e de baixo custo, que empregam LED/RGB como fonte de radiação e LDR como receptor, têm sido usados em diversas aplicações analíticas no meio científico. Neste trabalho foi desenvolvido um fotômetro baseado em um RGB e LDR ligados a um microcontrolador do tipo ATMEGA8-16PC da Atmel para processamento dos dados com finalidade de analisar diferentes amostras de teor alcoólico a abaixo custo. Os resultados foram comparados com um espectrofotômetro comercial no qual foi possível observar a semelhança entre os resultados. Em seguida foi realizado uma regressão linear no qual se obteve um ajuste bastante satisfatório validando assim o trabalho.

\section{INTRODUÇÃO}

De acordo com o decreto $\mathrm{n}^{\circ} 6.871,4$ de junho de 2009, entende-se por cerveja "a bebida obtida da fermentação alcoólica do mosto cervejeiro oriundo do malte da cevada e água potável, por ação da levedura , com adição de lúpulo." A variação de um ou mais componentes existentes no processo como: tempo, temperatura de cozimento, fermentação, maturação ou matéria-prima, é a responsável pela existência de uma grande variedade de tipos de cervejas espalhadas pelo mundo (Soares, 2011).

Estima-se que o consumo e a produção de bebidas alcoólicas é uma das atividades mais antigas realizadas pelo homem. Alguns historiadores indicam que por volta de 8.000 anos a. C. a cerveja começou a ser fabricada. A produção teve seu início com as civilizações da Suméria, Babilônia e Egito (Paiva, 2011). Posteriormente os povos bárbaros que ocuparam a Europa durante o Império Romano, os de origem germânica, obtiveram destaque no processo de fabricação da cerveja, sendo esse povo responsável pela adição de lúpulo na bebida no século XIII, conferindo as características básicas da cerveja atualmente (Mega, J. F, et al, 2011). 
A produção de cerveja coloca o Brasil em $3^{\circ}$ lugar no ranking mundial, com 124 milhões hL/ano, ficando atrás de países como China (44,8 bilhões de hectolitros) e Estados Unidos (22,7 bilhões de hectolitros) (Brunelli,2012), no entanto quando compara-se o consumo nacional os valores são baixos, ficando atrás dos países europeus girando em torno de 64 litros per capita/ano (Paiva,2011). No entanto esse mercado cervejeiro tem se mostrado crescente nos últimos anos, isso é resultado do aumento da faixa etária da população acompanhado pelo aumento do poder aquisitivo, refletido pela atual estabilidade econômica (Reinold,2011) (Santamech,2011).

O teor alcoólico está relacionado ao tipo de cerveja, sendo este um importante fator de qualidade. A maioria das cervejas do tipo Pilsen existentes no mercado possuem um teor alcoólico em torno de 5\%. Devido a isso, é interessante o uso de técnicas capazes de analisar o nível de álcool presente nas cervejas. Uma das técnicas usadas para a determinação a concentração de álcool é a espectroscopia na região do visível (MARCO et al., 2006). Por outro lado esta técnica necessita de mão de obra especializada além do uso de instrumentos apropriados. Os equipamentos mais usados são o fotômetro e o espectrofotômetro. Estes equipamentos, apesar de usarem uma técnica simples, são de custo expressivo para que pequenos produtores de cerveja artesanal possam adquiri-los para seu uso no dia a dia. Contudo, existem cada vez mais, o uso de tecnologias alternativas capazes de desempenhar esta função a custo muito reduzido. Entre elas está o de poder confeccionar um próprio fotômetro com materiais simples como LED's (light-emitting diode) e LDR's (Light Dependent Resistor) (FÁBIO, 2010). O objetivo principal deste trabalho foi desenvolver um fotômetro UV-Visível de baixo custo com tecnologia embarcada e software próprio para medir níveis de álcool em cervejas.

\section{MATERIAIS E MÉTODOS}

Para a montagem do equipamento, foi utilizado como componentes principais um Light Emitting Diode como fonte de emissão de luz na faixa do visível uma vez que é possível modular os comprimentos de onda emitidos, um e Light Dependent Resistor como detector de luminosidade e um microcontrolador do tipo ATMEGA8-16PC para o processamento das informações e varredura do processo conforme mostrado na Figura 1.

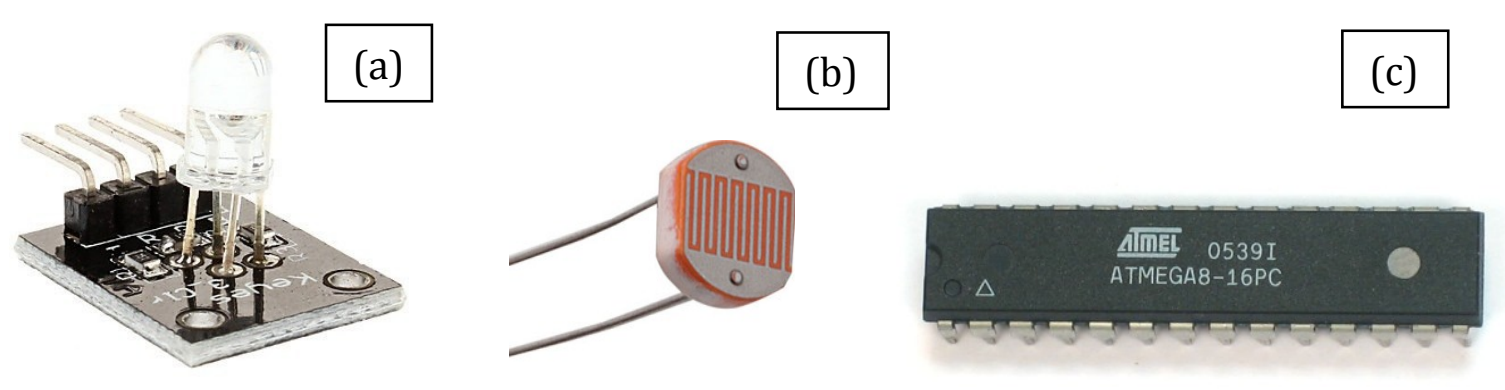

Figura 1 - Componentes Light Emitting Diode LED/RGB (a), Light Dependent Resistor LDR (b) e Microcontrolador ATMEGA8-16PC (c). 
Para a construção do corpo do equipamento, foi utilizado uma caixa plástica com tampa de encaixe na qual foram pintados com tinta preta fosco a fim de se evitar a interferência luminosa provocada tanto pelo meio externo quanto por reflexão interna do próprio equipamento (Figura 2-a). Foi desenvolvido uma porta de acesso para a introdução da cubeta com as amostras (Figura 2-b) de forma que possa ser usado o equipamento continuamente, bastando apenas retirar ou inserir a cubeta.

Todos os componentes foram montados na estrutura conforme visto na Figura 2-c e Figura 2-d.



Figura 2 -Montagem do Fotômetro com pintura preto fosco (a), Porta de acesso à cubeta (b), montagem dos componentes internos (c) e vista do equipamento finalizado (d).

Em seguida, foi desenvolvido um algoritmo (linguagem $\mathrm{C}$ ) capaz de realizar a varredura dos comprimentos de onda na região do visível. Procurou-se varrer a faixa que vai do Violeta à região do Vermelho. O algoritmo modula a intensidade do Light Emitting Diode - Red Green Blue fazendo com que o mesmo emita energia no comprimento de onda pré-estabelecido para a análise dos resultados.

Também é possível medir os dados lidos pelo Light Dependent Resistor onde os quais são enviados através de comunicação USB para um computador pessoal. O programa foi compilado e salvo no microcontrolador do equipamento deixando automático todo o processo de análise das 
amostras sendo apenas necessário ligar o fotômetro a um computador pessoal.

$\mathrm{O}$ valor pago para desenvolver o equipamento foi de $\mathrm{R} \$ 85,60$ incluindo todos os componentes, corpo físico e materiais de apoio a confecção do fotômetro. Os gastos do projeto estão muito além do custo médio de um equipamento comercial orçado em $\mathrm{R} \$ 3.354,36$.

Em seguida, foi necessário realizar a calibração do equipamento. Para isso, o fotômetro em operação foi ligado a um notebook como pode ser visto na Figura 3-a. A Figura 3-b mostra a varredura dos espectros realizada pelo algoritmo na qual será tratada com uma programação específica para os comprimentos de onda lidos pelo instrumento.

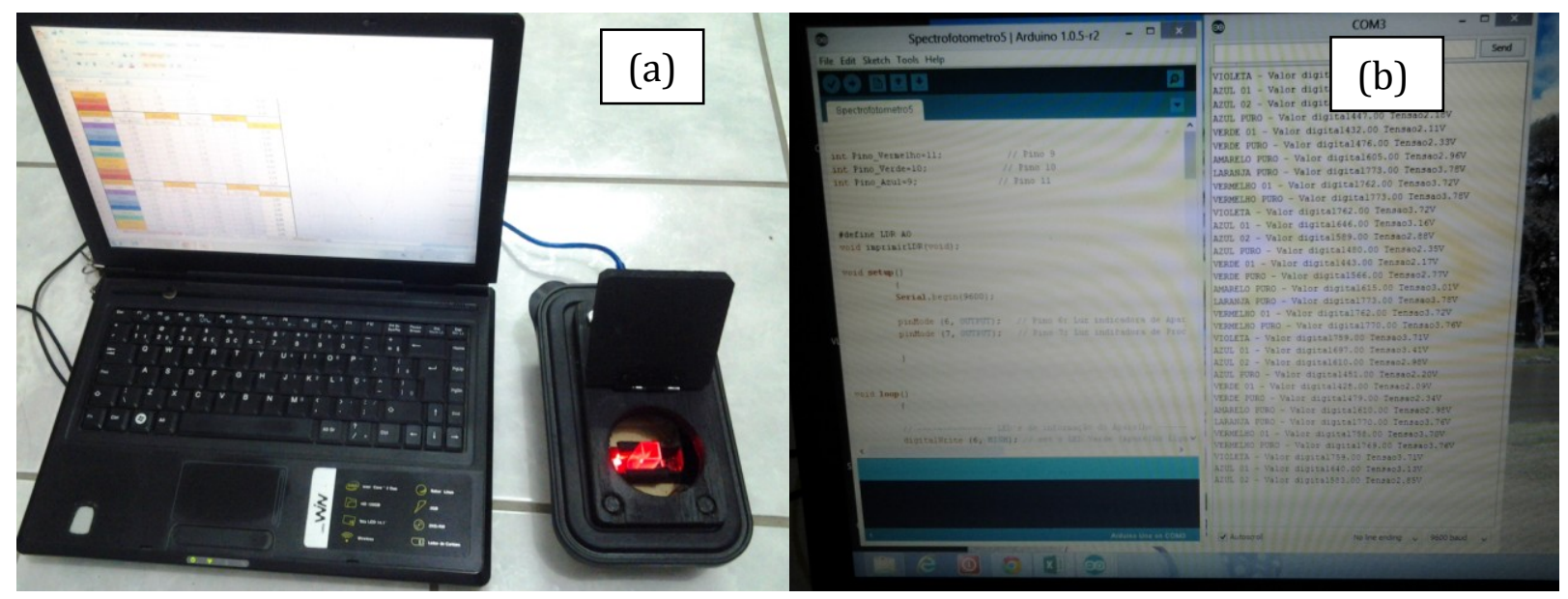

Figura 3 - Fotômetro ligado a um notebook (a). Varredura dos sinais (b).

Foi preparado amostras com teor alcoólico conhecido. Para isso, foi necessário utilizar uma cerveja tipo Pilsen sem álcool (Figura 4 - a) como padrão. Em seguida, foi diluído etanol anidro na cerveja a fim de se obter a concentração alcoólica (em volume) desejada. Foi preparado amostras com concentração de $0 \%, 5 \%, 10 \%, 15 \%$ e $20 \%$ de álcool que serviram de dados para a curva de calibração do equipamento.

O Script para análise do resultado do fotômetro foi desenvolvido em MATLAB ${ }^{\circledR}$. O resultado da concentração é obtido através de ajustes polinomiais de sexta ordem onde cada faixa de cor gera uma curva de intensidade do sinal versus concentração. Para a calibração do equipamento, o script gera um polinômio para cada comprimento de onda gerado pelas amostras conhecidas, que é tratado como o padrão, como visto na Figura 5. Para cada nível de energia absorvido, o programa verifica qual o comprimento de onda mais significativo fazendo assim o melhor ajuste. Com isso, o programa consegue ser calibrado em função de amostras conhecidas.

Para analisar uma amostra desconhecida (Figura 4 - b) o script procura qual a concentração que tem o mesmo sinal de saída da amostra, resolvendo uma equação polinomial de $3^{\circ}$ grau, onde apenas uma das 3 soluções é dada como correta. A solução correta é a que não apresenta parte imaginária e que se encontra na faixa de concentração dos padrões conhecidos obtidos em 
laboratório. Com isso o Script demonstra a concentração estimada da amostra desconhecida plotando um gráfico de superfície.

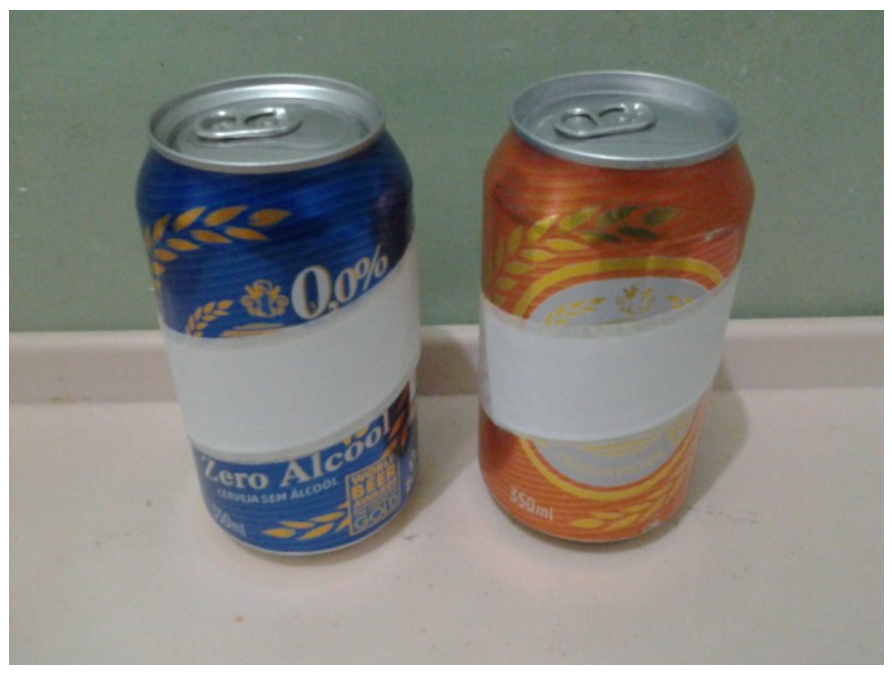

Figura 4 - Cerveja sem álcool tipo Pilsen (a). Cerveja com álcool tipo Pilsen (b).

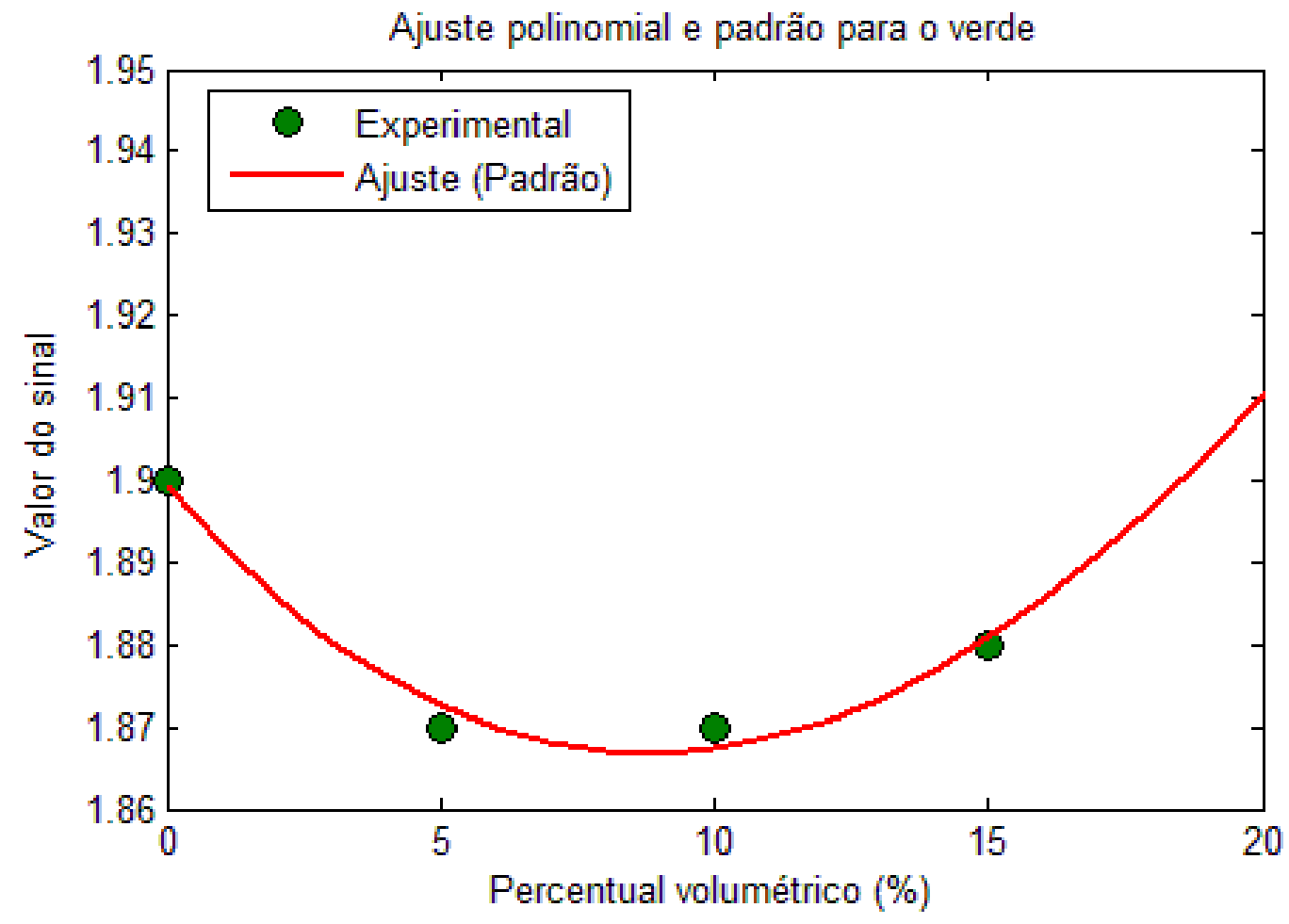

Figura 5 - Curva do ajuste padrão para o teor alcoólico em função do sinal. 


\section{RESULTADOS E DISCUSSÃO}

Os resultados das varreduras feitas nas amostras com $0 \%, 5 \%, 10 \%$ e $15 \%$ podem ser vistos na Tabela 1. A Figura 4 mostra o gráfico de Absorbância pelo comprimento de onda.

Tabela 1: Resultado das tensões em volts obtido pelas varreduras dos espectros nas mostras de cervejas com concentração alcoólica de $0 \%, 5 \%, 10 \%$ e $15 \%$.

\begin{tabular}{c|cccc} 
Comp. de Onda & Tensão (0\%) & Tensão (5 \%) & Tensão (10\%) & Tensão (15 \%) \\
\hline $400 \mathrm{~nm}$ & $\mathbf{3 , 6 9}$ & $\mathbf{3 , 6 9}$ & $\mathbf{3 , 6 7}$ & $\mathbf{3 , 6 7}$ \\
$410 \mathrm{~nm}$ & $\mathbf{3 , 1 9}$ & $\mathbf{3 , 1 8}$ & $\mathbf{3 , 1 7}$ & $\mathbf{3 , 1 7}$ \\
$430 \mathrm{~nm}$ & $\mathbf{2 , 8 3}$ & $\mathbf{2 , 8 1}$ & $\mathbf{2 , 8 1}$ & $\mathbf{2 , 8 0}$ \\
$440 \mathrm{~nm}$ & $\mathbf{2 , 1 2}$ & $\mathbf{2 , 1 0}$ & $\mathbf{2 , 1 0}$ & $\mathbf{2 , 1 0}$ \\
$500 \mathrm{~nm}$ & $\mathbf{1 , 9 0}$ & $\mathbf{1 , 8 7}$ & $\mathbf{1 , 8 7}$ & $\mathbf{1 , 8 8}$ \\
$520 \mathrm{~nm}$ & $\mathbf{2 , 4 2}$ & $\mathbf{2 , 4 2}$ & $\mathbf{2 , 4 0}$ & $\mathbf{2 , 4 1}$ \\
$580 \mathrm{~nm}$ & $\mathbf{2 , 8 7}$ & $\mathbf{2 , 8 7}$ & $\mathbf{2 , 8 5}$ & $\mathbf{2 , 8 6}$ \\
$590 \mathrm{~nm}$ & 3,73 & 3,73 & 3,72 & 3,72 \\
$650 \mathrm{~nm}$ & 3,68 & 3,67 & 3,66 & 3,66 \\
$700 \mathrm{~nm}$ & 3,73 & 3,72 & 3,71 & 3,71
\end{tabular}

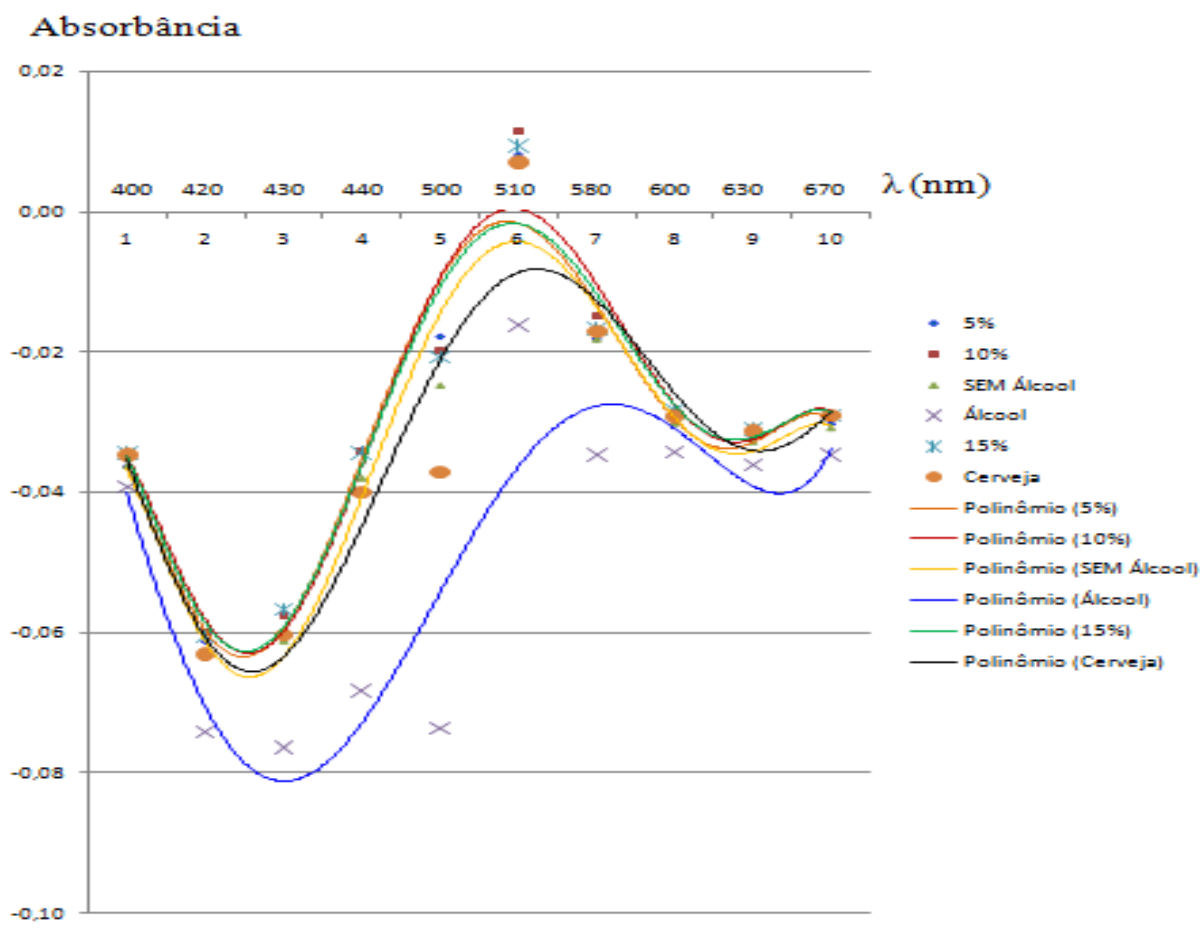

Figura 4 - Gráfico da Absorbância pelo comprimento de onda do teor alcoólico em cerveja. 
Em seguida, foi possível plotar um gráfico de resposta para a intensidade do sinal lido pelo instrumento em função do teor alcoólico da cerveja do tipo Pilsen e do comprimento de onda. A Figura 5 mostra o gráfico de superfície para a intensidade do sinal lido pelo fotômetro.

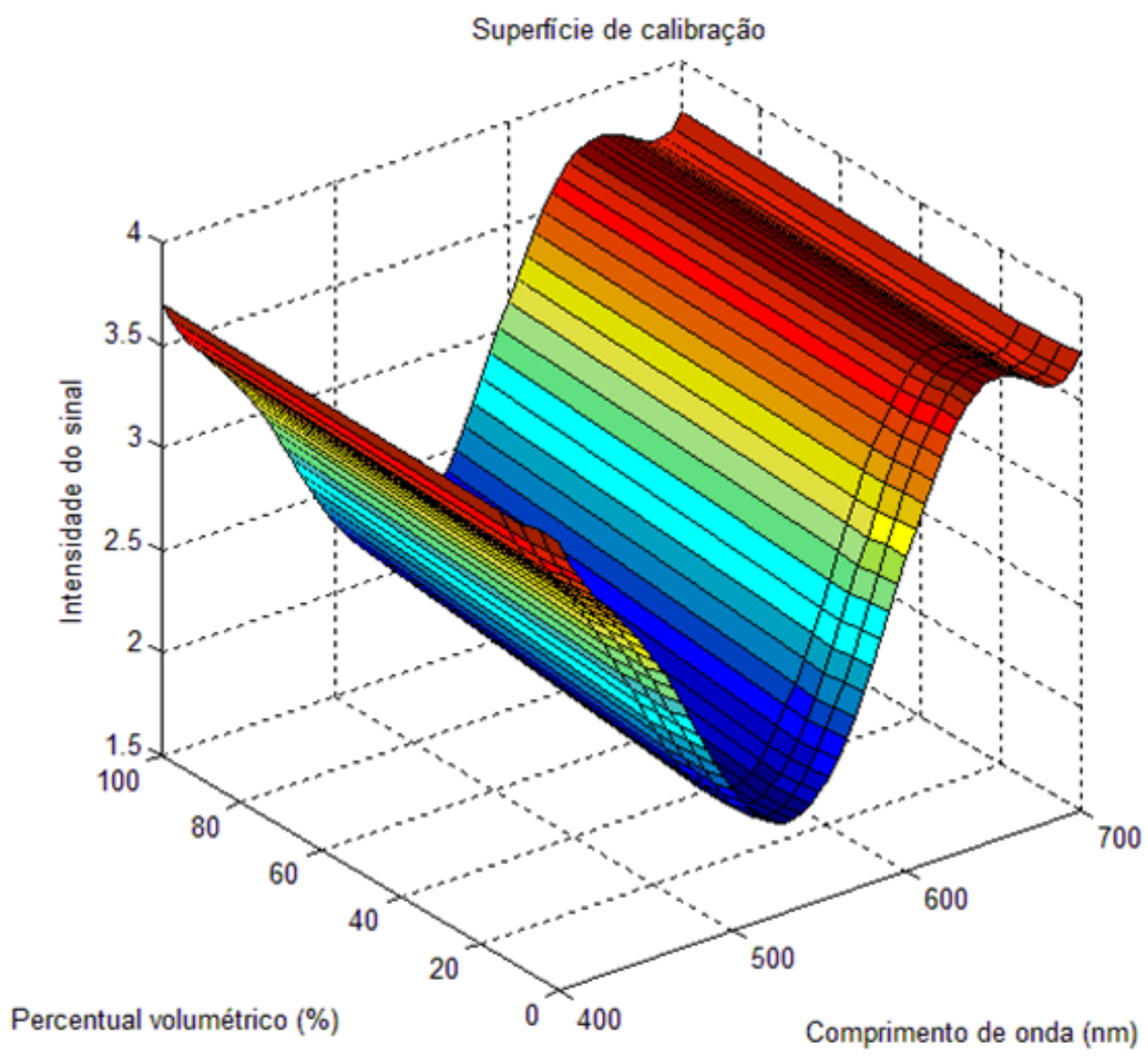

Figura 5 - Gráfico de superfície da intensidade do sinal lido pelo instrumento em função da concentração de álcool e do comprimento de onda associado

Foram realizados testes nas amostras de cervejas do tipo Pilsen encontradas no mercado. Os resultados das concentrações, em volume, de álcool contido nas amostras podem ser vistos na Tabela 2 mostrada a seguir.

Tabela 2: Resultado do teor alcoólico, em volume, presente nas cervejas.

\begin{tabular}{|c|c|c|c|}
\hline Análise & Cerveja 1 & Cerveja 2 & Cerveja 3 \\
\hline Laboratório & $4,70 \%$ & $5,30 \%$ & $4,81 \%$ \\
\hline Fotômetro & $4,69 \%$ & $5,23 \%$ & $4,78 \%$ \\
\hline
\end{tabular}




\section{CONCLUSÃO}

O resultado obtido pelo fotômetro desenvolvido na Universidade Federal Rural de Pernambuco foi bastante satisfatório, uma vez que os teores alcoólicos lidos pelo instrumento condizem com os resultados obtidos em laboratório. Com um custo de montagem orçado em cerca de $2,5 \%$ do valor de um instrumento comercial, o fotômetro sugerido neste trabalho atende as necessidades de um equipamento de baixo custo sendo acessível a qualquer pessoa.

\section{REFERÊNCIAS}

BRUNELLI, L. T. Produção de Cerveja com Mel: Características Físico-Químicas, Energéticas e Sensorial. 2012. 103 f. Dissertação (Mestrado em Agronomia - Energia na Agricultura). Faculdade Ciências Agronômicas da Unesp. Botucatu-SP, 2012.

FÁBIO ALEXANDRE COSTA MOTA, desenvolvimento de um fotômetro com fins didáticos, Universidade Federal do Amazonas, Instituto de Ciências Exatas, Programa de pós-graduação em química, dissertação, manaus, 2010.

MARCO A. M. SOUTO, MARINA M. OKADA, ISAURA A. OKADA, SÉRGIO, DOVIDAUSKAS. A determinação de nitrato em águas por espectrofotometria UV: usos e precauções. Rev Inst Adolfo Lutz, 65(1):66-70, 2006.

MEGA, J. F., NEVES, E. ANDRADE, C. J. A Produção de Cerveja no Brasil. Revista Citino, v. 1, n. 1, p. 34-42, 2011.

PAIVA, G. M.. Estudo do Processamento e Mercado de Cervejas Especiais no Brasil. 2011. $90 \mathrm{f}$. Monografia (Tecnólogo em Alimentos). Faculdade de Tecnológia Termomecânica. São Bernardo dos Campos - SP, 2011.

REINOLD, M. R. Elaboração do Mosto: Curso Intensivo para Cervejeiros Práticos.1990.

SANTARNECH D. G. Novos Desafios e Expectativas Positivas. Revista de Bebidas: Fc Santos, 2011. Ano 10. Anuário 2011

SOARES, N. Tempo de Mudanças. Revista Indústria de Bebidasn 205/ Ano 23 - 2011. 